\title{
La UNED ante las interacciones sociales digitales: el caso de audiovisuales en línea
}

Coordinador, Programa de Producción de Material Audiovisual, UNED; lufallas@uned.ac.cr

Recibido: 22 de julio de 2011

\section{RESUMEN}

Ante la sociedad digital, las universidades, en particular la UNED, deben de vislumbrar las nuevas necesidades y posibilidades de integración de su labor, de manera activa y permanente, con la cotidianidad de sus usuarios potenciales. La plataforma de audiovisuales es una primera aproximación a abrir estos espacios y ejemplo del manejo del ser institucional virtual como herramienta para la integración de la población estudiantil a la labor académica. Se pretende que estudiantes y profesores comenten, interactúen y construyan, no bajo la lógica de un horario o de tareas, sino como actividad constante y transversal. La universidad se presenta como espacio permanente de creación, donde lo didáctico y lúdico se mezclan, para favorecer la integración de la investigación y criticidad como acciones constitutivas del quehacer humano y no como exclusividades del proceso científico.

\section{PALABRAS CLAVE}

Internet, plataforma de audiovisuales, redes sociales, diseño,manejo de imagen, universidad
Aceptado: 3 de octubre de 2011

\begin{abstract}
SUMMARY
Universities and particularly UNED as are dealing with digital societies must discern the new needs and integration possibilities of their work, actively and permanently with the every day life of their potential users. The Audiovisuals' platform is a first attempt to open those spaces and an example of handling the isntitution's virtual identity as tool for the integration of students to academic work. It pretends that students and teachers comment, interact and build, not under a logic of schedules and homeworks, but as a constant and transversal activity. University portraits itself as a permanent space of creation, where didactic and recreational goals are mixed to favor the integration of investigation and criticity as constitutives tasks of all human action and not as cientifical work exclusiveness.
\end{abstract}

\section{KEY WORDS}

Internet, audiovisuals' platform, social networks, design, image management, university

\section{INTRODUCCIÓN}

El proceso creativo nos permite compartir nuestro ser cultural y representar nuestras identidades y nuestra lucha común por voz y construcción de sentido. Cuando escuchas nuestras historias poéticas aprendemos a leer el mundo a través de las diferencias en forma y contenido... Los estudiantes también aprenden sobre ellos mismos y su educación al meditar en el evento... Este trabajo también provee una forma alternativa de instrucción para estudiantes acostumbrados a lo que Paulo Freire (1970) llama "método bancario" de educación, donde los estudiantes son tratados como contenedores pasivos que reciben, en lugar de interactuar con o transformar el conocimiento (Hanley, 2007). 
La interconexión entre computadores cambió desde 1991 hasta el presente. Lo que en un inicio fue principalmente el intercambio de datos que representaban textos escritos o series numéricas, evolucionó hacia el soporte primordialmente de audio y vídeo. Según Cisco Visual Networking Index, para 2015 un 90\% de todo el tráfico de información por Internet estará constituido por vídeos. Exponencialmente la Internet se sustenta más en imágenes en movimiento y en su movilidad. Está cambiando de un mundo virtual a una re-presentación de la realidad. En los espacios virtuales anteriores los recursos como el texto escrito y lugares fijos de conexión eran el paradigma de la experiencia del internauta. La red se liberó de las computadoras de escritorio y ahora puede ser accedida desde los teléfonos móviles. La norma ahora es que se carguen en diferentes portales vídeos hechos por diversión, arte, cobertura noticiosa y de opinión sobre la cotidianeidad.

Más revolucionario aún, la comunicación cara a cara en tiempo real entre sus usuarios es una realidad. Internet se torna así en una especie de ojo omnipresente, donde cualquier cosa pasada, presente e incluso futura puede ser vista, revivida frente a nosotros. $Y$ si en algún momento el cine o la televisión pudieron intentar alcanzar algo similar a esto, Internet tiene una ventaja significativa: no depende de emisarios privados particulares de mensajes, sino que, de hecho, está enclavada en una dinámica de comunicación multipunto.

Las posibilidades de Internet siguen ampliándose al ritmo que las dinámicas de comunicación humana continúan su transformación. Las redes sociales de amistad se han convertido en foros donde lo que se comparte depende exclusivamente de los intereses particulares de cada individuo. Se da un rango tan amplio de interacción que incluye la discusión de los últimos sucesos mundiales, grupos de estudiantes que se reúnen para colaborar en el desarrollo de un curso o compartir nostalgias de tiempos pasados. Esta nueva dinámica de las relaciones sociales implica el publicar -es importante este término de publicar, pues mucho de lo que se hace a nivel consciente e inconsciente tiene la mismas implicaciones de las decisiones y prácticas editoriales que caracterizan a los medios de comunicación tradicionales en ámbitos como: impacto de la noticia, relevancia, generación de opinión o reacción en el público metadesde el nacimiento de un hijo, hasta la constitución del almuerzo que se está consumiendo. Lo que se vislumbra es una nueva concepción de la vida como un espectáculo público, esto acarrea el desvanecimiento de las distancias temporales y físicas, toda vez que la relevancia y necesidad de inmediatez ya no se determinan por el valor social de la información, sino por un interés individual.

Nos enfrentamos a un mundo que ya no es escrutado por un grupo de periodistas, sino que la actividad humana es reportada, en su pena y gloria, trascendencia y nimiedad, por un conglomerado en constante aumento de ojos electrónicos. El medio ciertamente sigue siendo extensión de nuestros sentidos, pero con capacidades de interconexión insospechadas. El meollo del asunto es su impacto en la medida en que nuestros pequeños mundos se truecan en aldeas globales y al mismo tiempo estos espacios globales se dividen, a su vez, en intereses, conglomerados aislados de afinidades. Esta dinámica de agrupamiento favorece las crecientes alter-comunidades no-presenciales -mundos dentro de otros mundos- que incluso facilitan la aparición de lugares o grupos sociales únicamente accesibles a través de Internet.

¿Cómo pueden las instituciones educativas insertarse en estas esferas, cómo pueden convertirse en faros en el ambiente informativo y comunicativo, a veces oscuro e incierto, de Internet? ¿Cómo aprovecharse de estas dinámicas sociales de la virtualidad para potenciar el aprendizaje y desarrollo del conocimiento? 


\section{- La educación superior como red social}

Las instituciones educativas han tratado de romper los muros de concreto de los salones de clases para permitir la educación a distancia. Antes de contar con tantos recursos de comunicación como en el momento actual, la UNED, a semejanza de otras instituciones, buscó modalidades alternas para aquellos que, por su situación geográfica o económica, no podían estar en un sistema presencial de educación superior, pudieran acceder a la formación universitaria.

Contemporáneamente, las nuevas tecnologías brindan otra oportunidad para que la educación cambie radicalmente el ambiente de la enseñanza y su dinámica. Poner el conocimiento científico al alcance de grupos de otra forma excluidos puede detonar su interés para apropiárselo y producir el propio, dado que ya no seguiría siendo una imposición externa sino una búsqueda personal.

Sobre el particular, Heuer comenta que Marsick y Watkins consideran que los adultos prefieren el aprendizaje informal y por tanto incidental. Esto por cuanto así deciden el qué, dónde y cómo desean aprender, siendo incluso sus propios evaluadores (Hever, 2007). Muchos años antes de que esta posibilidad fuera tangible, Isaac Asimov ya era bastante entusiasta sobre la manera en que el paradigma educativo se transforma toda vez que el individuo es movido por su propia curiosidad e intereses a la búsqueda del conocimiento. El autor, al ser entrevistado por Moyers en 1988, argumentaba sobre su optimismo al hablar de cómo incluso un interés por el béisbol, algo netamente lúdico, puede fomentar el aprendizaje de la matemática (Moyers \& Asimov, 1988).

Ahora, con la realidad de la avalancha de información que ha propiciado la Internet, es evidente, desde la academia, la necesidad de una guía que colabore en la orientación de los intereses de los individuos hacia un corpus que permita la apropiación y generación de conocimiento a partir del fomento de las competencias. Por competencias entendemos la tolerancia, comprensión y elaboración de conclusiones a partir de criterios diversos, la búsqueda autónoma de información, la curiosidad permanente como motor del aprendizaje.

Muchas de estas competencias, ante todo la búsqueda proactiva de insumos, son comunes al uso lúdico de la Internet; otras, en cambio, como la tolerancia y la construcción colaborativa, son necesidades que se evidencian ante el afloramiento de grupos aislacionistas o discriminadores que se cohesionan en su exclusión sobre las plataformas sociales o sitios web. Igualmente, como meta-transformación, está la concepción de la red como una herramienta usada primordialmente en la formación permanente y no como método de escape o disociación con el entorno. La universidad debe intervenir esta red para fortalecer su potencial educativo e investigativo, visto como un ocio creativo, sobre las aplicaciones de entretenimiento superficial.

Asincronismo y ubicuidad son las claves para las nuevas dinámicas de comunicación en Internet y también de la educación a distancia; pero el aula de puertas abiertas de Internet, incluso como una extensión del típico salón de clases, no puede ser abordada de la misma manera. Se le podría ver más como un ágora antigua, donde finalmente todos tienen voz y un espacio. Las personas se reúnen cada una con un particular cúmulo de conocimiento que será desplegado en este medio para promover la investigación y la comprensión mutua.

Este contexto de interacción mediado por la Internet tiene muchas conversaciones paralelas. Giroux, comentado por Sandlin, considera que los adultos, cuando son educandos, deben transformarse en productores culturales. Esto sucede si, en los salones de educación crítica, se fomenta que cada cual cree su propio conocimiento y cultura. Así se irán construyendo nuevas y más democráticas realidades y esferas 
culturales (Giroux 2004, citado por Sandlin, 2007). Con esta propuesta la responsabilidad del estudiante es cada vez mayor sobre su proceso educativo, al estar a cargo de la búsqueda de fuentes de información, proponer temas de investigación, participación colaborativa y crítica en círculos estudiantiles de debate académico, entre otras dinánimicas posibles. A su vez el rol del maestro se ve enfrentado a una transformación radical, que lo lleva a ser más un tipo de gestor o promotor académico, garante además de la rigurosidad científica en los intercambios inter-estudiantiles.

¿Se alcanzará esta utopía? ¿Cómo podrían ser convocados los usuarios de estos medios a estos espacios de tipo educativo? ¿Debería de haber espacios particulares identificados como educativos? ¿Cómo enmarcar estas acciones? Algo está claro, el diseño -entendido como los elementos que hagan del espacio un lugar atractivo, de fácil utilización y que favorezca la interacción- es un dinamizador de las relaciones humanas mediadas por Internet.

\section{- Avatares universitarios}

Usuarios de blogs y espacios web personales, entre otros, invierten una considerable cantidad de tiempo diseñando, definiendo la forma en que ellos mismos van a ser presentados en Internet. Para algunas personas, la vida no sólo refleja lo que los medios dicen, la vida misma es su auto-representación mediática. Esto quiere decir que los individuos están adentrándose en un ámbito común de las empresas: las relaciones públicas. La identidad ya no es un acontecimiento sino un proceso reflexivo más o menos consciente, cuasi-publicitario.

Esto es de gran importancia para las instituciones educativas, ahora se vive en una era donde el concepto de diseño de Donald Norman puede, de alguna manera, ser aplicado a mucho más que los aparatos cotidianos, se le puede aplicar al común de las personas. Sin embargo, como Norman establece, el diseño es más profundo que solamente la imagen. De hecho está unido a la búsqueda de la mejor funcionalidad posible de un objeto. Norman llama la atención al resultado de las investigaciones de la psicóloga Alice Insen y sus colegas. Ellos han encontrado una relación directamente proporcional entre el estar feliz y los procesos de reflexión y pensamiento creativo. De ahí que Norman considere esenciales a las emociones positivas para el aprendizaje, la curiosidad y el pensamiento creativo (Norman, 2004).

Lo anterior significa que un sitio web deja de ser, en el caso de una universidad, simplemente una plataforma de servicios, para convertirse en un avatar de lo que considera su identidad. Este avatar a su vez debe de tener la capacidad estética de reflejar los valores de la institución y primordialmente de generar empatía y agrado por parte de los usuarios. Es decir, la relación a través de la web con estudiantes y público en general es ahora sensual, entendido este término bajo lo que Norman concibe como un diseño que, ante todo, toca los elementos sensoriales más primarios.

Esta nueva relación usuario-institución está impulsada porque, a su vez, el manejo de la identidad en Internet, como se apunta arriba, con mayor o menor complejidad, es asumida por los individuos también como un producto de venta. Ellos igualmente se basan, más o menos concientemente, en elementos de diseño para lanzar su ser virtual en la web. Las aplicaciones y extras que brindan los sitios de redes sociales están claramente dirigidos a eso, la personalización de la página del individuo, en parte, pasa por la creación de un nuevo ser-mediático, una virtualización idealizada que asume el rol de expresión particular del yo.

Esa expresión deliberadamente busca agradar, ya sea a la generalidad o al grupo particular del cual se considera integrante. Así, la universidad también debe de pensar en esa forma de agradar, para así atraer participantes a sus procesos académicos, ya no por la coacción de las situaciones o realidades particulares, 
sino mediante el involucramiento voluntario en la aventura del conocimiento. Sin banalizar el ser universitario, este debe de buscar las herramientas de diseño que favorezcan su integración en estos procesos de socialización virtual-mediática.

Las universidades, así, deberían convertirse en personas-virtuales para poder posicionar sus servicios en la web. Las universidades públicas deben salir en búsqueda de "fans" que sucumban a sus encantos. Esto quiere decir que no se pueden limitar a ofrecer oportunidades de estudio, materiales educativos o programas de extensión, deben abrir espacios o foros reflexivos para la discusión y participación formativa. La diferencia entre un chat con una universidad como anfitriona o moderadora y cualquier otro chat o blog en Internet radicará en que la universidad garantice la precisión de las opiniones dadas. De tal manera que estos espacios no se pretenden autoritarios, sino veraces y fiables. Una activación de la rigurosidad académica como elemento promotor de la interacción en web. Esta exigencia debe ser un reto para quien se integra a estos círculos, no un elemento limitante de su participación. Eso quiere decir que requerirá de procesos de inducción en la argumentación de posiciones, estudio de fuentes y referencias bibliográficas. Con la pretensión de que estas exigencias propias de la academia sean los dinamizadores de una participación plural y activa de amplios colectivos.

En tales espacios virtuales, independientes de los cursos de carrera, profesores, investigadores, estudiantes y público en general podrían discutir abiertamente y promover la búsqueda del conocimiento y la veracidad. Sería un entorno educativo basado en una lógica que simula la interacción de las sinapsis neuronales. Es decir, el conjunto del conocimiento se generaría a través de la conmutación de ideas y saberes, una construcción común y socializada del saber. Cada uno de los participantes aportaría, desde su realidad, para el crecimiento del grupo y, de esta interacción, a la vez, para la formación del individuo.
Estos macroforos serían también insumos y espacios de práctica para los procesos educativos de los estudiantes regulares. La pertinencia, pluralidad y actualidad de los contenidos académicos se fomentaría desde múltiples espacios de participación abierta. Más que conciencia crítica, la universidad sería un cabildo de análisis e interacción social, fortalecido por la transversalidad de conocimientos de sus participantes, con una exigencia permanente en pro de la rigurosidad científica. El resultado esperado sería la transformación cualitativa de la era de la información en la del conocimiento.

No obstante, esta dinámica no puede estar limitada al texto escrito. Como se elaboró anteriormente, los medios de expresión de las sociedades postmodernas son variados. La expresividad visual está profundamente arraigada en las nuevas generaciones y puede llegar a ser incluso más natural para ellas que la escritura. Es una suerte de recuperación de la oralidad, sustentada en las posibilidades de intercambio de vídeo, generado individualmente, más o menos improvisado, pero que en el esquema propuesto para la universidad, debería estar sustentado en criterios académicos. Además, las nuevas tecnologías hicieron del texto audiovisual una creación mucho más accesible que tan solo cinco años atrás y esta tendencia se mantendrá. Así que ya no es una especialidad o una forma de expresión ajena, la comunicación por vídeo es tan sólo una alternativa más, una cotidiana.

\section{- La UNED visual}

La Universidad Estatal a Distancia (UNED) de Costa Rica, en 2010, lanzó la Plataforma de Audiovisuales, un servicio de distribución de vídeo en línea. Inspirada en espacios como Youtube, la universidad permite el acceso a sus producciones audiovisuales abiertamente, de manera asincrónica y gratuita. Este proyecto, en su primera etapa, permite a los visitantes compartir los materiales audiovisuales de la 
UNED en sus redes sociales o blogs; es decir, la socialización de las producciones se hace en espacios extra-universitarios.

En lo inmediato, se trabaja para la activación de la publicación de comentarios en la misma página en que está el vídeo, no obstante, tal labor requiere, para cumplir con el espíritu académico, de un administrador de estos comentarios, previendo justamente generar un entorno respetuoso y comprometido con el quehacer universitario, que a su vez pueda gestionar respuestas $\mathrm{u}$ orientaciones a los participantes del espacio que así lo requieran.

El objetivo a largo plazo es permitir a estudiantes, docentes e investigadores de la UNED publicar, dentro del mismo sitio, vídeos realizados por ellos mismos, en una suerte de foro permanente o revista audiovisual. Para favorecer esta actividad, una de las opciones sería que se les de acceso a los fondos audiovisuales de la universidad, a una selección de las imágenes y a entrevistas sin editar, recabadas en más de 30 años de producción. Este insumo permitiría, aún si no se tiene a disposición una cámara de vídeo, que los involucrados puedan expresar sus opiniones mediante el lenguaje audiovisual. Cuando se alcance este punto la plataforma logrará múltiples metas. Primero, la interacción y la exposición de creaciones visuales, las institucionales y las de los usuarios, deberán ayudar a promover la necesidad de una alfabetización audiovisual de la población. Esto es quebrar la etapa de percepción referencial de las reconstrucciones visuales y generar una consciencia de su faceta ideológica de construcción de sentido.

En sí, se habla de dinámicas que aportarían a paliar lo que Robinson denuncia de los esquemas tradicionales de educación, que típicamente han separado el intelecto de la emoción. La creatividad, asociada primordialmente a lo artístico, no es tomada en cuenta para lo científico, esto por una mala concepción de que la expresión individual de las ideas no tiene espacio en la ciencia. Se debe retomar la creatividad como el elemento que lleva a la interrelación entre arte y ciencia, puesto que ambas salen perjudicadas de su separación (Punset \& Robinson, 2011).

Una vez que a los espectadores se les promueva publicar sus propias propuestas audiovisuales, al producir sus mensajes, se irá evidenciando que cualquier texto de estos implica una posición ideológica. Este descubrimiento permitirá una aproximación crítica hacia los medios. Máxime cuando, en el mismo lugar, múltiples visiones sobre un mismo tema estarán coexistiendo.

Ahora, ciertamente, esto no es un suceso único, dado que espacios como este ya existen en Internet. Lo que ofrece la UNED es tener un proceso para garantizar la debida sustentación de las opiniones dadas. Así, los usuarios deberán también practicar técnicas de argumentación e investigación para conseguirle un espacio a sus propuestas. Esto no sería un control sobre los aspectos ideológicos, sino una demanda de rigurosidad académica. El objetivo es certificar la fiabilidad del material publicado.

Una dinámica como esta es común para el circuito intelectual, pero es extraña para el público en general. De tal forma que la UNED aspira a alcanzar una transformación en este ámbito y promover con ello la sociedad del conocimiento. El paso adelante que la universidad dará es, en un ambiente virtual, lograr uno de los principios propuestos por Freire: que en lugar de la instrucción, la educación lo que busque sean formas de despertar, promover, incentivar el deseo de las personas por el conocimiento.

Consecuentemente, la UNED propondrá materiales audiovisuales que pretenden multiplicarse en una miríada de nuevas respuestas, cuestionamientos y ampliaciones. Esto coincide con la concepción de la universidad como espacio para fomentar el intercambio e incentivar la búsqueda de conocimiento, promoviendo la solución, de común acuerdo, de los problemas sociales 


\section{CONCLUSIÓN}

La Plataforma de Audiovisuales, con sus perspectivas de crecimiento e inserción en la vida universitaria, es un aporte para que la UNED, como una universidad de aprendizaje a distancia, pueda abrir un punto virtual de encuentro, referencial para el futuro de la educación. Sus estudiantes, investigadores, profesores y profesionales, así como personas de todo el mundo, van a tener un espacio para la creación de conocimiento a través de la discusión e investigación y, a la vez, van a presionar el avance de las posibilidades de la comunicación audiovisual, de tal manera que una nueva pedagogía mediada pueda ser mutuamente elaborada.

Esta pedagogía encuentra un antecedente en la concepción de Dewey (1916) respecto a la comunicación y la educación. No solo es la vida social idéntica a la comunicación, sino que toda comunicación ( $y$ por tanto toda genuina vida social) es educativa. Tomar parte de un proceso de comunicación enriquece, ya sea por recibir o elaborar un mensaje. Al exponerse a las ideas de otras personas, en diferentes proporciones, las concepciones propias se afectan. Al elaborar un mensaje, el creador debe re-conocer lo que desea expresar, encontrando cuáles son los valores comunes con el entorno en que se encuentra, pues la eficacia de su comunicación pasa por conseguir un nivel de referencialidad y empatía con quienes la reciben. Vivir en común, bajo esta concepción, es un acto de educación, la comunicación con el grupo tiene implicaciones en el estímulo de la imaginación, intercambio de experiencias y crea responsabilidad por la exactitud e intensidad de la declaración y el pensamiento.

Este espacio pedagógico va más allá del lugar virtual de encuentro, llega hasta el ambiente en el cual estudiantes y profesores viven. Toma los contenidos universitarios hasta esos espacios cotidianos $y$, en ese intercambio, el conocimiento se enriquece para los propósitos académicos y también es mayormente apropiado por los estudiantes. UNED hace un llamado a todos los interesados en hacer constructos cognoscentes $y_{1}$ con ello, en forjar una nueva dinámica de aprendizaje que conjunta los usos sociales de la web 2.0 con las exigencias académicas.

Favorecer esta dinámica es preparar a la institución para las exigencias venideras con el desarrollo de la web 3.o. En ese contexto futuro, realidad aumentada, movilidad permanente, una red semántica e interacción social, serán los parámetros del quehacer en los ambientes virtuales e integrados permanentemente con el espacio concreto y tangible de la existencia. Un camino hacia una red que cada vez se parece más al cerebro humano, pues, según Kevin Kelly, estamos a menos de tres mil quinientos días para que la cantidad de conexiones de la Internet iguale al promedio de sinapsis neuronales (Kelly, 2007).

En esa posibilidad del surgimiento de una conciencia global, multipunto y plural, la integración de la universidad como espacio de encuentro común, desde ya, es fundamental para darle un poco de cordura a lo que puede presentarse como una realidad apabullante. Es pasar a ser un faro itinerante, no portadora de una luz que se aferra a la costa, sino gestora de la claridad mar adentro, en los distintos puntos de la tormenta.

\section{BIBLIOGRAFÍA}

Cisco. (2011). Cisco Visual Networking Index: Forecast and Methodology, 2010-2015. Recuperado del sitio de Cisco: http://www.cisco. com/en/US/solutions/collateral/ns341/ns525/ ns537/ns705/ns827/white_paper_c11-481360_ ns827_Networking_Solutions_White_Paper. html, ocutbre 2011.

Dewey, John. (1916). Democracy and education: An introduction to the philosophy of education. California, NuVision Publications, 2007.

Hanley, Mary S. (2007). "Old school crossings: Hip hop in teacher education and beyond". New Directions for Adult and Continuing Education, $115,35-44$. 
Hever, Barbara P. (2007). "Using popular media to build literacy". New Directions for Adult and Continuing Education, 115, 55-62.

Kelly, Kevin. (2007). Predicting the next 5000 days of the web [Charla en vídeo]. Recuperado del canal TedTalksDirector en el sitio web de Youtube: http://www.youtube.com/ watch?v=yDYCf 4 ONh5M, agosto 2011.

Moyers, B. (entrevistador) y Asimov, I. (entrevistado). (1988). El Mundo de las Ideas. [Entrevista en vídeo]. Recuperado del sitio web de Youtube: http://www.youtube.com/watch?v=olU051 qXuPQ\&feature=related, agosto 2011.
Norman, Donald A. (2004). Emotional design: Why we love (or hate) everyday things. New York: Basic Books.

Punset, E. (entrevistador) y Robinson, K. (entrevistado). (2011). El sistema educativo es anacrónico. Redes. Recuperado del sitio web de Televisión Española: http://www.rtve.es/television/20110304/redes-sistema-educativoanacronico/413516.shtml, agosto 2011.

Sandlin, Jennifer A. (2007). "Popular culture, cultural resistance, and anticonsumption activism: An exploration of culture jamming as critical adult education". New Directions for Adult and Continuing Education, 115, 73-82. 